\title{
TREATING CERVICAL CANCER WITH HERBS: A REVIEW
}

\author{
ANITHA JOSEPH, KIRUTHIKA DHANRAJ, SIVAKUMAR RAMALINGAM, RENUKA SARAVANAN*
}

Department of Chemistry and Biosciences, Shanmugha Arts, Science, Technology and Research Academy Deemed to be University, Srinivasa Ramanujan Centre, Kumbakonam, Tamil Nadu, India. Email: renuka@src.sastra.edu

Received: 03 March 2018, Revised and Accepted: 28 March 2018

ABSTRACT

Medicinal plants have been on the forefront where research on the anticancer agent is planned. This review mainly focuses on several such as medicinal plants Rosmarinus officinalis, Solanum nigrum, Kaffir lime, and Garcinia nujiangensis used in the treatment of cervical cancer and the secondary metabolites derived from different plant sources. Plant molecules such as cisplatin, curcumin (-)- epigallocatechin (EGC)-3-gallate, EGC, epicatechin3-gallate, and other catechins that have a wide range of biological properties and the molecular mechanism with different cells were reviewed. This review will promote the research on the development of a plant-derived anticancer drug with lesser or no side effects and aid in understanding the mechanism of action of several plant-derived molecules.

Keywords: Cervical cancer, medicinal plants, plant molecules, lesser side effects

(C) 2018 The Authors. Published by Innovare Academic Sciences Pvt Ltd. This is an open access article under the CC BY license (http://creativecommons. org/licenses/by/4. 0/) DOI: http://dx.doi.org/10.22159/ajpcr.2018.v11i7.25580

\section{INTRODUCTION}

The most common malignant tumor among women throughout the world is cervical cancer. It is found to be the second most common type of tumor. It is found to have high mortality rate [1] which accounts for more than 500,000 new cases and approximately 275,000 deaths occur [2]. There are various methods used to treat cervical cancer with chemotherapy, radiotherapy, and surgery. It is recommended for patients at an early stage, and fertile women could undergo surgical treatment. The effectiveness of chemotherapy and radiotherapy is specific for cancer cells, and it may possibly destroy the whole normal cell.

In cases, where platinum-based chemotherapy is used for the treatment of locally advanced cervical cancer, it has been identified that up to $35 \%$ of the patients already treated with radiation or surgery, develop recurrent metastatic disease. Effective therapies and innovations are required for treating advanced and refractory cervical cancer, as the response post-treatment is often substandard and temporary [3]. Researchers believed that the dietary phytochemical agents may influence chemotherapy treatment and help cure patients with cancer [4]. In this, plants continue to play a significant role both medically and economically [5]. There are several sources of anti-cervical cancer drugs which are derived from spices, herbs, and vegetables, and a variety of plants are used in folk medicine. One of the strategies is to consider natural products. In the modern system of medicine, about $25 \%$ of prescriptions contain active principles derived from plants. Plant-derived drugs play dominant roles in the treatment of cervical cancer, such as camptothecin, taxol, and combretastatin [6].

\section{HERBS IN THE CURING OF CERVICAL CANCER}

Traditional medicine is still used by approximately $65-80 \%$ of the world's population in developing countries as a source of primary health care. The main reason for the use of traditional medicine is due to their affordability, accessibility, and cultural beliefs [7]. The World Health Organization estimates that majority of the people depend on herbs for their health care. The most commonly used treatments are surgical, radiation, and hormone treatments but they have severe side effects. Medicinal plants can be promising source of novel therapeutic agents, especially for cancer. It has been estimated that out of 250000 plants species existing on earth approximately 1000 species are known to have anticancer potential. Thousands of species have been screened through bioassays for the search of novel plant-based anticancer drugs [8].
Anisomeles malabarica is an herb that belongs to the family of Lamiaceae which possess antispasmodic, diaphoretic, antipyretic, and antiperiodic properties. It is also reported to contain secondary metabolites such as anisomelic acid, ovatodiolide, geranic acid, citral, betulinic acid, and beta-sitosterol. Thus, the study proved that the n-hexane and chloroform extracts of $A$. malabarica inhibit proliferation and induce death in human papillomaviruses (HPV) 16-positive cervical cancer cells by apoptosis and necrosis [9]

Berriescontain awide range of phytochemicals with biological properties that include antioxidant, anticancer, anti-neurodegenerative, and antiinflammatory activities [10]. Black raspberries (Rubus occidentalis) are a rich natural source of chemopreventive phytochemicals [11]. Ethanol extract of black raspberries induced apoptosis in all cervical cell lines (HeLa, SiHa, and C-33A) with varying degrees of potency and demonstrated a significant growth inhibitory and apoptotic activating activities in a dose- and time-dependent manner. Hence, the study found that black raspberries and their bioactive components represent promising candidates for food-based chemoprevention strategies for cervical cancer [12].

Boswellia serrata is an important medical plant from Burseraceae family. It possesses various pharmacological properties that include anti-inflammatory, antimicrobial, and antitumor property [13]. The plant is obtained from species B. sacara, B. frereana, and B. serrate. Monoterpene, diterpene, and triterpene, and boswellic acid are the main constituents of $B$. serrata, which can induce apoptosis in cancerous cells and the hydroalcoholic extract of this plant causes the death of cervical cancer cells (HeLa cell) [14].

Boerhaavia diffusa L. (Nyctaginaceae), which is commonly known as "punarnava" [15], is a perennial creeping herb that is used for the treatment of various ailments [16]. It is containing phenolic compounds, namely alkaloids and amino acids and is reported to exhibit strong antioxidant properties [17]. Pharmacological studies have demonstrated that it exhibits a range of properties such as diuretic antifibrinolytic, anticonvulsant, and antibacterial. The extract of this plant is found to shown analgesic and anti-inflammatory property, hepatoprotective activity, immunomodulatory activity, and anti-proliferative properties. Thus, the study reports that, at a concentration of $300 \mu \mathrm{g} / \mathrm{mL}$, the ethanolic crude root extract exhibits cytotoxic effect and causes 30\% cell death in HeLa cell line. Moreover, a 
methanol:chloroform fraction could inhibit the proliferation of human cervical cancer cell line (HeLa) through S-phase inhibition, induced antiproliferative activities, inhibition of DNA synthesis and induction of apoptosis [16].

Bullet wood tree, also called Spanish cherry (Mimusops elengi L.), belonging to family Sapotaceae which are widely used in the treatment of different ailments. Studies investigated the cytotoxic potential of methanolic leaf and bark extracts of $M$. elengi against human cervical cancer cell line (SiHa) by 3-(4,5-dimethylthiazol-2-yl)-2;5diphenyl tetrazolium bromide (MTT) assay. There is an increase in apoptotic bodies from $0.24 \%$ to $60 \%$ and $69 \%$ after treatment with extracts. These extracts exhibit significant cytotoxic effect by inducing apoptosis. These findings suggested that extracts and compounds from this plant could be useful for preventing and treating human gynecologic cancer disease especially cervical cancer [18]

Cassia tora Linn (Leguminosae) is a well-known ayurvedic medicinal plant that acts as a laxative, antiperiodic and is used to treat leprosy, ringworm, bronchitis, and cardiac disorders. Seeds of CT express antioxidant activities and contain many active substances including chrysophanol, emodin, and rhein. The antiproliferative activity of $C$. tora methanolic leaf extract with Cisplatin was studied on human cervical cancer cells (HeLa) and the proliferation was measured by MTT assay. The extract is found to induce a marked concentration-dependent inhibition on proliferation, reduced DNA content and apoptosis in HeLa cells [19].

Cinnamon, a spice widely used in culinary, has been shown to exhibit diverse biological functions including anti-inflammatory, antioxidant, antimicrobial, anti-diabetic effects, and anti-tumor activity. Cinnamon could be trusted to be a promising candidate for restricting the growth of cervical cancer cells. The aqueous cinnamon extract, from the bark of Cinnamomum cassia L. (family of Lauraceae) on human cervical cancer cell ( $\mathrm{SiHa}$ ), the study suggested that it could be proposed to be a potent anticancer drug candidate in cervical cancer cells as it significantly affected the growth rate of $\mathrm{SiHa}$ cells in a dose-dependent manner and also induced apoptosis through loss of mitochondrial membrane potential [20].

The medicinal plant Cordia dichotoma belonging to the family Boraginaceae is found to have antioxidant, juvenomimetic, antifertility, anti-inflammatory, and various other pharmacological activities. The methanolic extract of $C$. dichotomous on HeLa cancer cell line induced apoptosis by various mechanisms either by DNA fragmentations or by mitochondrial depolarization or accumulation of reactive oxygen species (ROS). The presence of phenolics and carotenoids in their leaves has potent antioxidant and anticancer activity; thus, it could be a new potent cancer chemopreventive or chemotherapeutic agent for human cervical cancer cells because of its anticancerous activity [21].

Curcumin is normally acquired from the rhizome of turmeric (Curcuma longa) and has been generally utilized as a traditional medicine because of the various restorative properties. It has antioxidant and pleiotropic effects by modulating the multicellular signal pathways such as inflammation, invasion, proliferation, metastasis, and cell cycle. Thus, curcumin is found to be a traditional medicine with therapeutic effect against cancer cells. At the concentration of $\mathrm{IC}_{50}, \mathrm{HeLa}$ and $\mathrm{SiHa}$ were treated in the absence as well as in the presence of curcumin. Cur-liposome showed a significant increase in apoptosis population when treated with the same dose of curcumin when compared with the cells treated with raw curcumin. With the incorporation of didecyldimethylammonium bromide apoptosis in both cells was promoted. Hence, the study recommends that the preparation of curcumin as nano liposome provided higher toxicity than free-curcumin treated at the same concentration [22].

The root of $C$. longa contains curcumin, a natural compound and the fruits of strawberries, raspberries, and walnuts contain ellagic acid a polyphenol. The combination of curcumin and ellagic acid at various concentrations showed better anticancer properties than either of the drugs when used alone as evidenced by MTT assay. Besides this, curcumin and ellagic acid also restore p53 induce ROS formation and DNA damage. The mechanistic study further indicated that curcumin and ellagic acid show anti-HPV activity as evidenced by a decrease in the HPV E6 oncoprotein on HeLa cells and provides an important lead for anticancer therapeutics for the treatment of cervical cancer [23].

Extracts from Inula viscosa (L.) Ait, Retama monosperma (L.) Bois, Ormenis mixta (L.) Dumont, Ormeniseriolepis Coss, Rhamnus lycioides (L.), Berberis hispanica Bois and Reut, and Urginea maritima (L.) Baker are studied. The cytotoxic activity of selected plants was studied on the human cervical carcinoma cells lines, SiHa and HeLa, harboring HPV16 and HPV18, respectively. Among the 7 medicinal plants tested, methanolic extracts from Inula viscosa (L.) Ait, R. monosperma (L.) Bois, and Ormeniseriolepis Coss. Extracts showed significant growth inhibitory effects in both SiHa and HeLa cells compared to the control due to the presence of active compounds [24].

Ganoderma applanatum, a member of the species of the basidiomycete, is called "Elfvingia applanata." This mushroom has been used often in folk medicine for the treatment of various ailments including cancer [25]. The methanolic extract of G. applanatum elicited dosedependent cell death on HEp-2 cells after $24 \mathrm{~h}$ of treatment, with an IC $_{50}$ value of $43.2 \mu \mathrm{g} / \mathrm{ml}$. It exhibited toxicity particularly toward tumor cells compared to normal Vero cells. The anticancerous activity of G. applanatum is due to the presence of $\gamma$-terpinene, D-limonene, cis-2methyl-4-pentylthianes, s-dioxide, $\beta$-cymene, and $\alpha$-terpinolene which play a major role in inducing apoptosis [26].

In the southwest region of China, Garcinia nujiangensis, an endemic species is located. A new compound Nujiangexanthone A (NJXA), is isolated from the leaves of $G$. nujiangensis, which exhibits cytotoxicity against an array of human tumor cell lines. Potent anticancer activity identified that NJXA acts as a crucial agent in treating cervical cancer. The results indicate that NJXA exhibited selective cytotoxicity against cervical cancer cells. It further induced G0/G1 cell cycle arrest in HeLa and SiHa cells by downregulating the cyclins A, B1, and E1, as well as cyclin-dependent kinases 2,4 , and 6 , during the selective restoration of p27 [27].

Kaffir lime (Citrus hystrix) is a member of the citrus family [28], and the leaf of this plant contains alkaloid, flavonoid, terpenoid, tannin, and saponin compounds. The leaves and fruit extracts are found to have antioxidant activity, free radical scavenging ability, antimicrobial activity, and anti-inflammatory activity. Based on the $\mathrm{IC}_{50}$ values, chloroform extract of Kaffir lime had the effective potential to reduce HeLa cell viability. Hence, the studies suggested that the kaffir lime leaf extract reduced the viability of cervical cancer cells in micromolar concentrations [29].

The crude methanolic extract of the leaves of Leea indica of the family Vitaceae was examined for their antitumor activity against Ehrlich ascites carcinoma cells. The compound at the dose of $40 \mathrm{mg} / \mathrm{kg} /$ day significantly decreased tumor weight. Glycosides, mollic acid arabinoside and mollic acid xyloside, were first isolated from the fresh leaves of $L$. indica, inhibited the growth of $\mathrm{Ca}^{2+}$ Ski cervical cancer cells with $\mathrm{IC}_{50}$ of $19.21 \mu \mathrm{M}$ through two signaling mechanisms - the activation and release of mitochondrial pro-apoptotic proteins known as caspases under the control of Bcl-2 family of proteins or upregulated expression of pro-apoptotic receptors on cancer cells [30].

Paulownia coreana is used as both health food and medicine for the treatment of cancer as well as other major infectious diseases [7]. From the leaves of $P$. coreana, isoatriplicolide tiglate (PCAC) was isolated. Anti-proliferation activity is found in cervical cancer cell lines when treated with the chloroform extract of $P$. coreana. This, in turn, even at a low concentration $(<10 \mu \mathrm{g} / \mathrm{mL})$ subdues the proliferation of cancer cells and cell growth and at a high concentration $(>50 \mu \mathrm{g} / \mathrm{mL})$ induces apoptosis. From this, it has been concluded that PCAC can act 
as antiproliferation agents, inducing cell cycle arrest in the S/G2 phase and caspase-dependent apoptosis, particularly against cervical cancers by activates caspase- $8,-9$, and -3 [31].

Portulaca oleracea is a ubiquitous garden weed that has been traditionally used as anti-diabetic and anti-inflammation agent [32]. It has high antioxidant property, vitamins, dietary minerals, and iron. $P$. Oleracea aqueous extracts exhibited antiproliferative and apoptotic effects against HeLa cell line in a dose- and time-dependent manner [33].

Polygonum aviculare is a member of Polygonaceae-Dock family. The herbal extract of this plant has astringent properties. It can be a natural potent chemopreventive and chemotherapeutic plant for patients identified with cervical cancer. Hence, the study suggested that methanolic extract of $P$. aviculare has a potent anti-growth effect and showed the cytotoxic and apoptotic effect on Hela-S cervical cell line and may be exploited as a potential source for developing novel drugs against cervical cancer [34].

Acetone extract of $S$. discolor (SDE) inhibited the growth and survival of cancer cells to varying degree, but the inhibition was found to be maximum in cervical cancer cell lines. There was no significant toxicity induced in normal cells. The cell death was mediated through apoptosis. There was increased mitochondrial membrane depolarization, expression of Bax, caspase-9, caspase-3, and cleaved - poly ADP-ribose polymerase (PARP) indicating that SDE induced caspase-dependent apoptosis in HeLa cells. Moreover, SDE caused cell cycle arrest in G2 phase in HeLa cells. Cytotoxicity nature of the plant led to the isolation of chrysin which was the major phytochemical constituent present in $S$. discolor and also the active principle responsible for the antiproliferative activity for cervical cancer cells [35].

Satureja is from the genus of the mint family Lamiaceae. Satureja bachtiarica Bunge was shown that tannins, fatty substances such as terpenoids and phenolics compounds are the main effective and bioactive components in its extracts. The hydroalcoholic extract of S. bachtiarica Bunge has an anticancer effect which can inhibit the growth through dose-dependent and time-dependent effect on Hela cancer cells, and in higher doses, the growth of cancer cells was more inhibited, and also it did not have any significant effect on natural fibroblast cells [36].

Solanum nigrum is an herbal plant that has been used in traditional folk medicine because of its diuretic and antipyretic effects, and it contains steroidal glycosides, steroidal alkaloids, steroidal oligoglycosides, solamargine, and solasonine. The study indicated that $S$. nigrum aqueous extract could inhibit the uterine cervical carcinoma through multiple functions by stimulating the host immune system which resulted in massive necrosis in tumor tissues. At the same time, by inhibiting PCNA gene expression, it arrested the cell cycle and triggered apoptosis in tumor cells [37].

Violet plant is the Herbaceous plants. It is reported to have a number of medicinal features including antioxidant, anti-inflammatory, antimicrobial, sedative, and also anti-cancer activities [38]. Aqueous extract of this plant has a strong inhibitory effect on proliferation of cervical cancer, and the active ingredient of the plant responsible for this effect is ethyl acetate. Thus, the studies suggest that the plant that has cytotoxic and anticancer effects on HeLa cells [14].

Vitex agnus-castus is used as a traditional medicine in gynecological condition. A V. agnus-castus fruits extract has been shown to exhibit antitumor activities in different human cancer cell lines. A crude extract was prepared with ethanol from dried ripened V. agnus-castus fruits which have cytotoxicity against human cervical carcinoma. Hence, the study showed that the cytotoxic activity of Vitex extract may be attributed to the effect on cell growth, and cell death occurs through apoptosis, and this apoptotic cell death may be attributed to increased intracellular oxidation by Vitex extract treatment [39].
Violaceae ignobilis is a member of Violaceae plant family. Vigno 5 is a natural cyclopeptide from $V$. ignobilis and its action on cervical cancer cells from a study found that vigno 5-treated HeLa cells were killed off by apoptosis in a dose-dependent manner within $24 \mathrm{~h}$ and were characterized by the appearance of nuclear shrinkage, cleavage of PARP, and DNA fragmentation. The mitochondrial pathway of apoptosis revealed that cytochrome $\mathrm{C}$ is released from mitochondria to cytosol, associated with the activation of caspase- 9 and -3 , and the cleavage of PARP. Thus, the study indicated that vigno 5 induces apoptosis in parts through the mitochondrial pathway, which is associated with a release of cytochrome $\mathrm{C}$ and elevated activity of caspase- 9 and caspase- 3 in HeLa cells [40].

Xylopia aethiopica, also known as African guinea pepper, is an angiosperm that belongs to the family Annonaceae and has great nutritional and medicinal values. The extracts from $X$. aethiopica are found to elicit antibacterial, antifungal, antiplasmodial, antioxidant, hypotensive, and diuretic effects. The anticancer activity of $X$. aethiopica fruit extract (XAFE) was showed that it arrests C-33A cells at G0/G1 and G2/M phases of the cell cycle, by increasing p53 and p21 gene expression and inhibits cell proliferation and also induces apoptosis. Thus, the study suggested that XAFE could be a potential therapeutic agent against C-33A cervical cancer cells [41].

\section{PLANT MOLECULES AS ANTICERVICAL CANCER AGENTS}

Several classes of anticancer drugs have been developed, and many of them are of natural origin. Natural products have been the mainstay of cancer chemotherapy for the past 30 years. However, most of the currently used anticancer drugs cause undesirable side effects due to lack of tumor specificity and multidrug resistance. Therefore, the search for potent, safe, and selective anticancer compounds is crucial for new drug development in cancer research. Natural products, due to the structural diversity, provide excellent templates for the construction of novel compounds. $60 \%$ of currently used anticancer agents are derived in one way or another from natural sources [35]. Many chemical compounds from herbal plants have been explored for their potential anti-tumor activity and safety [42]. Most herbs contain antioxidant agents that could be consumed to prevent cancer or potentiate chemotherapy, and also, a number of phytochemicals isolated from medicinal plants have been shown to decrease cell proliferation, induce apoptosis, retard metastasis, and inhibit angiogenesis [4].

Amoora rohituka is an evergreen tree which is used as herbal medicine for cancer, tumor, liver, and spleen diseases [43]. Amooranin is a triterpene acid, isolated from A. rohituka. The stem bark possesses significant anticancer potential that inhibits the growth and spread of cervical cancers by arresting G2/M phase of the cell cycle and by inducing apoptosis [44]. Due to the presence of alkaloids including alkaloids rohitukin, amooranin, amoorastatin and $12 \alpha$-hydroxyamoorastatin, and complex liminoids, the chloroform stem bark extract of rohituka, Aphanamixis polystachya has cytotoxic effects on HeLa with an $\mathrm{IC}_{50}$ of $25 \mu \mathrm{g} / \mathrm{ml}$ by induction of DNA damage in the form of micronuclei and induction of apoptosis [45].

Apigenin, a widely distributed plant flavonoid has also been shown to inhibit the growth of HeLa cells and was reported to be a potential antitumor agent. Significant reduction in the viability of HeLa cells by apigenin at 37-74 $\mu \mathrm{M}$ was observed, and the $\mathrm{IC}_{50}$ value was found to be $35.89 \mu \mathrm{M}$. Hence, the study reported that apigenin acted by triggering the apoptotic pathway, characterized by induction of $\mathrm{G}_{1}$ arrest, DNA fragmentation, increased expression of p21/WAF1, caspase-3, mediators of apoptosis and decreased in the protein expression of an antiapoptotic factor the Bcl-2 protein [31].

Caffeic acid (CA), one of the major bioactive compound of Rosmarinus officinalis $\mathrm{L}$ has been identified to possess both anti-inflammatory and anticancer activities. CA, as a phenolic diterpene, exerting protective effects associated with inflammatory cytokines. The researchers found that carnosic acid exerted anti-tumor ability in vitro supported by 
upregulation of apoptosis and ROS production in cervical cancer cells. Furthermore, acceleration of ROS led to the phosphorylation of c-Jun $\mathrm{N}$-terminal kinase and activation of endoplasmic reticulum stress, promoting the progression of apoptosis through stimulating caspase- 3 expression. Hence, carnosic acid seems to be an effective compound used for cervical cancer in clinical treatment [42].

Cisplatin remains one of the most effective current chemotherapeutic agents; however, metal complex synthesis has increased to produce new antineoplastic drugs with DNA binding and apoptotic activities in tumor cells and less toxicity for patients. Studies evaluated the cytotoxic activity of a novel copper (II) complex (LQM402) against cervical cancer cell lines and found that it exhibited selective cytotoxicity against HeLa and Ca Ski cells. Thus, it might be used as a potential therapeutic agent against cervical cancer and may be a promising and safe anti-cervical cancer compound [46].

Cisplatin is the cell cycle non-specific agent and the most common drug that is extensively applied in chemotherapy. Cisplatin inhibits the division of tumor cells by triggering obstacles in DNA replication. Matrine is isolated from Sophora flavescens with functions of clear heat and dry dampness and belongs to tetracyclic thiazides involved in traditional medicinal functions; it also has the functions of protecting the cardiovascular system, improving patients' immunologic function, and protecting liver along with antiviral and anti-tumor roles. The combined treatment of matrine and cisplatin, with a synergistic effect, can notably inhibit the growth of tumor in U14 rats with cervical cancer, by significantly improve the immunologic function of rats and decrease the toxic reaction in the process of treatment [47].

Coffee is a rich source of dietary phenolic phytochemical, including caffeic acid (CA). CA is reported to have a wide variety of biological activities, including antioxidant, antithrombosis, antihypertensive, antifibrosis, antiviral, and antitumor properties. The inhibitory effect of CA on cancer cell proliferation by an oxidative mechanism in humans HT1080 fibrosarcoma cell line has been reported. The study emphasizes the mechanism by which CA inhibits cell proliferation in human cervical cancer cells (HeLa and ME-180) [48].

Curcumin (1,7-bis (4-hydroxy 3-methoxyphenyl)-1,6-heptadiene3,5-dione) is a natural polyphenolic compound extracted from the rhizome of the medicinal plant $C$. longa Linn (also known as turmeric). Curcumin has been used in food additive, cosmetic, and as a traditional herbal medicine for its various biological activities. The therapeutic value of curcumin demonstrated that it possesses anti-inflammatory, antioxidant, anti-carcinogenic, thrombo suppressive, cardioprotective, anti-arthritic, and anti-infectious properties. Several studies reported that curcumin suppresses all three stages of carcinogenesis: Initiation, promotion, and progression. It has been clear that curcumin and its product (ferulic acid) holds great potential for the prevention and therapy of cervical cancer [49].

(-)-Epigallocatechin-3-gallate (EGCG), the most abundant and potent tea catechin, has anti-tumor activity against various types of cancers both in vitro and in vivo [50]. EGCG is one of the various polyphenols found in green tea [51]. Studies showed that EGCG suppresses the cervical cancer cell growth in vitro through induction of apoptosis and cell cycle arrests at the $G_{1}$ phase. It also has an ability to influence gene expression and provides an additional option for a new and potential drug approach for cervical cancer patients [52].

Frutalin is the $\alpha$-galactose, a binding lectin isolated from breadfruit seeds was obtained from two different sources: Native frutalin, purified from its natural origin, and recombinant frutalin was produced and purified from Pichia pastoris. Similar concentrations of n-frutalin and r-frutalin yielded identical magnitude of cytotoxicity on HeLa cells and possess a remarkable antiproliferative effect on HeLa cells. Hence, the study demonstrated that both lectins, native frutalin, and recombinant frutalin, have similar irreversible cytotoxic effects on HeLa cells, by inducing cell apoptosis and inhibiting cell proliferation [53].
Gallic acid (GA) is a polyhydroxy phenolic compound which is widely distributed in gallnuts, sumac, grape, green tea, oak bark, strawberry, lemon, banana, pineapple, witch hazel, and apple peel and has a wide range of biological functions [54]. GA has the inhibitory effect on HPVcontaining cells; inducing apoptosis and kills the cells containing HPV genome. Hence, the study suggested that GA can be a potential candidate for the development of anti-HPV agents and as a new lead for HPV infection therapy [55]

Genistein (4,5,7-trihydroxy isoflavone), the most abundant isoflavone found in soybeans, is believed to be a potent anticancer agent [56]. Genistein on human cervical cell lines (CaSki and ME180) reported that the augmentation of cell apoptosis induced by radiation may be due to the disruptive effect of genistein on the cell cycle, and it possesses a dose-dependent inhibition effect by $\mathrm{G}_{2} \mathrm{M}$ arrest, specifically with ME180 cells [57] and also a radiosensitizing effect on CaSki and ME180 cells [58].

Guizhi-Fuling-decoction (GZFLD) is a long-established Chinese medical formulation. GZFLD is composed of five kinds of medicinal plants, C. cassia BLUME (Cinnamomi cortex), Paeonialacti flora PALL (Peonies Radix), Paeonia suffruticosa ANDREWS (Moutan Cortex), Prunus persica BATSCH (Persicae Semen), and Poriacocos WOLF (Hoelen). Studies have disclosed that GZFLD could inhibit the development of cancer. It has also been shown that it suppresses the invasive ability of HeLa cells, inhibited matrix metalloproteinase (MMPs) expressions and activities, increased tissue inhibitors of metalloproteinases (TIMPs) expressions and activities, and furthermore restored the MMPs-TIMPs balance in HeLa cells in a concentration-dependent manner. Meanwhile, in vivo, GZFLD had significantly inhibited tumor growth and angiopoiesis [59].

Hesperetin is a flavonoid obtained from citrus fruits. It is found to have several bioactivities such as antiatherogenic, anti-inflammatory, and antihypertensive effects. The treatment of SiHa cells with hesperetin $\left(\mathrm{IC}_{50}\right.$ ) showed a marked concentration and time-dependent inhibition of proliferation and induced the $\mathrm{G} 2 / \mathrm{M}$ phase in a dose-dependent manner. There was an increased expression of caspase-3, caspase-8, caspase-9, p53, Bax, and Fas death receptor due to the attenuation of the mitochondrial membrane. Thus, the study shows that hesperetin exhibits a potential anticancer activity against human cervical cancer cell lines in vitro through the reduction in cell viability and the induction of apoptosis [60].

Iridomyrmecin, which is a plant iridoid compound, belongs to the polyphenolic group of naturally occurring compounds with significant antioxidant activity that exhibits potent cytotoxic effects and antitumor activity in HeLa cells through inducing early and late apoptosis, loss of mitochondrial membrane potential, sub-G1 cell cycle arrest, downregulation of PI3K/Akt protein expressions, and upregulation of IncRNA CCAT2 expression [61].

Isoliquiritigenin (ISL) a flavonoid found in licorice (legume) and shallot (Liliaceae). It has a potent antioxidant, anti-inflammatory, antiplatelet aggregation, and cancer-preventing properties. It also inhibits HeLa cells by blocking cell cycle progression in the $\mathrm{G} 2 / \mathrm{M}$ phase inducing apoptotic cell death, changes in the expression of Bax and Bak, decreasing levels of Bcl-2 and Bcl-XL, and subsequently triggering of the mitochondrial apoptotic pathway. Hence, the study suggested that ISL may be a promising chemopreventive agent against human uterine cervical cancer [62].

Kaempferol as flavonoids has antioxidant and anti-tumor properties and also shown to induce apoptosis in cancer cells. Cytotoxic activity of kaempferol against HeLa cells and human foreskin fibroblast (HFF) cell was determined by MTT assay. IC $_{50}$ values were $10.48 \mu \mathrm{M}$ for HeLa cells and $707.00 \mu \mathrm{M}$ for HFF Cells. Kaempferol suppresses the growth of HeLa cells as compared with HFF normal cells. Kaempferol induced cellular apoptosis and aging, by regulating the p13k/AKT and hTERT pathways. Studies suggest that kaempferol may be a useful adjuvant therapeutic agent in the treatment of cervical cancer [4]. 
Oleanolic acid (3ß-hydroxy-olean-12-en-28-oic acid) belongs to oleanane triterpene group of natural products, possesses a range of promising biological and medicinal effects including the antiproliferative activity. Oleanolic acid methyl vanillate ester exhibits anticancer activity on HeLa cervical cancer cells by inducing both early and late apoptosis in a concentration-dependent and time-dependent manner and increase in the ROS production [63].

Polyphenols, a natural and herbal extract is raising great interest as powerful and safe anticancer strategy for their broad range targeting capability and low side effects. It displays a wide variety of biological function including induction of apoptosis, growth arrest, and inhibition of DNA synthesis. Further, they are involved in modulation of signal transduction pathway and also interfere with each stage of carcinogenesis. Hence, polyphenols have been demonstrated to selectively inhibit tumor cell growth and may be a promising therapeutic tool for the treatment of cervical cancer [49].

Protoapigenone, also known as WYC02, a flavonoid was first isolated from Thelypteris torresiana, which contains in vitro cytotoxic activity against human cancer cells. It is found to be toxic to the cervical cancer cell lines C33A, HeLa, and SiHa. The studies demonstrated that the cervical cancer cells both in vivo and in vitro were suppressed by WYCO2 by the inhibition of PIK3 signaling pathway. This pathway has an inhibitory effect on cancer cell proliferation as well as inhibition of AKT1/MTOR activity, activation of caspases-9, -8 , and -3, also PARP cleavage and promotion of apoptosis [64].

Resveratrol is a polyphenol found in the seeds and skins of grapes, red wine, mulberries, and peanuts. It is demonstrated to inhibit proliferation and induce autophagy and apoptotic death in cervical cancer cells. Hence, the study suggested that resveratrol inhibits NF-kB and AP-1 transactivation suppressing the transcription of MMP-9, leading to suppression of migration and invasion of cervical cancer cells [58].

Ruthenium (Ru) complexes were showed cytotoxic and antiproliferative effects in different human cancers and also exert lower systemic toxicity in vivo as compared to platinum drugs [65]. It seems to be the most promising among the several metals investigated [66]. Lower systemic toxicity has been accredited to the unique ability of Ru compounds to preferably act on cancer cells. Ru complexes in principle may exhibit anticancer activity and toxic side-effects markedly different from that of Pt drugs. Ru complexes are emerging as most promising anticancer drugs in preclinical development in comparisons to other transition metal group and two complexes NAMI-A and KP1019 are currently in clinical trials. Thus, studies demonstrate that anticancer property of these two complexes was due to induction of apoptosis through p53 mediated pathway as well as the arrest of cells in the G2/M phase of cell cycle [65].

S. nigrum Linn. (Sn), known to be as Black Nightshade, is a dicot weed in the Solanaceae family. It has been in use in traditional Chinese medicine for many centuries [67]. Flavonoids (quercetin) and alkaloids (solasodine, solanine, and solamargine) are the primary phytoconstituents of $S$. nigrum which have been accounted for to act in different tumors [68]. It has inhibited the growth of cervical cancer [44] and showed significant antioxidant and antibacterial activities [69]. The effect of crude polysaccharide isolated from S. nigrum Linn (SNL-P) was examined both in vivo and in vitro on U14 cervical cancer cells [70]. The study indicated that the tumor growth inhibition of SNL-P administration might correlate with the reduction of tumor necrosis factor- $\alpha$ level of blood serum, which resulted in a massive necrosis in tumor tissues and the upregulation of Bax and downregulation of Bcl-2 and mutant p53 gene expression, which, in turn, triggered apoptosis in cervical tumor cells $[67,71]$.

Sulforaphane identified as one of the most widely investigated isothiocyanates and a potential chemopreventive agent which possesses anti-proliferative, anti-inflammatory, and antioxidant agent.
The effect of sulforaphane alone or in combination with gemcitabine on HeLa cells by cell viability assay was studied, and the results were confirmed by apoptosis assay. And also the effect of sulforaphane on the expression of $\mathrm{Bcl}-2, \mathrm{COX}-2$, and interleukin (IL)-1 $\beta$ by reverse transcription-polymerase chain reaction on HeLa cells was analyzed. A combination of sulforaphane and gemcitabine was found to increase the growth inhibition in a synergistic manner in HeLa cells compared to the individual drug. The expression analysis of genes involved in apoptosis and inflammation revealed significant downregulation of Bcl-2, COX-2, and IL-1 $1 \beta$ on treatment with sulforaphane. It exerts its anticancer activities through apoptosis induction and anti-inflammatory properties and provides the evidence demonstrating synergism between sulforaphane and gemcitabine which may enhance the therapeutic index of prevention and treatment of cervical cancer [72].

Tea polyphenols (TPP) are potent antioxidants that scavenge reactive oxygen and nitrogen species and chelate redox active transition metal ions. TPP contains several catechins compounds including EGCG, EGC, epicatechin-3-gallate, and other catechins that have a wide range of biological properties, such as anticancer, anti-allergic, antiinflammatory, and cancer chemoprevention activities. Bleomycin (BLM), an antineoplastic antibiotic based chemotherapeutic agent that is produced by Streptomyces verticillus and it is used primarily to treat various types of redox-influenced cancer, including testicular cancer, lymphoma, and squamous cell cancer of the head, neck, and cervix. The TPP-BLM treatment synergistically induced apoptosis through caspase- 3 , caspase- 8 , and caspase- 9 activation, Bcl-2 upregulation, and p53 overexpression. Studies suggested that TPP-BLM combination doses that are useful in the treatment of cervical cancer prevention or therapy [73].

Withaferin A (WA) is an active component of the medicinal plant Withania somnifera. It is found to exhibit inhibitory effects against several types of cancers and possesses anti-inflammatory, antitumor, antistress, antioxidant, immunomodulatory, hemopoietic, and rejuvenating properties. Studies reported that WA induces p53dependent apoptosis by repression of HPV oncogenes and upregulation of tumor suppressor proteins in human cervical cancer cells and can be further explored as a potent therapeutic agent for the treatment and prevention without deleterious effects [39,74].

\section{CONCLUSION}

The mortality rate due to different types of cancer has been increasing in spite of several treatment strategies for cancer. Plant-derived molecules or drugs could be an effective alternative for the treatment of different types of cancer. This review is an attempt to understand different types of plants and molecules which are used for the cancer treatment, especially for cervical cancer.

\section{REFERENCES}

1. Medina-Alarcón KP, Voltan AR, Fonseca-Santos B, Moro IJ, de Oliveira Souza F, Chorilli M, et al. Highlights in nanocarriers for the treatment against cervical cancer. Mater Sci Eng C Mater Biol Appl 2017;80:748-59.

2. Viswanathan AN, Dizon DS, Gien LT, Koh WJ. Chapter 58-Cervical Cancer. Clinical Radiation Oncology. $4^{\text {th }}$ ed. Philidelphia, PA: Elsevier; 2016. p. 1173-202.

3. Vooren KV, Curto A, Garattini L. Curing cervical cancer or preventing it: A case of opportunity cost in the long run? Vaccine 2014;32:6867-9.

4. Kashafi E, Moradzadeh M, Mohamadkhani A, Erfanian S. Kaempferol increases apoptosis in human cervical cancer heLa cells via PI3K/AKT and telomerase pathways. Biomed Pharmacother 2017;89:573-7.

5. Booth GM, Malmstrom RD, Kipp E, Paul A. Cytotoxicity of selected medicinal and nonmedicinal plant extracts to microbial and cervical cancer cells. J Biomed Biotechnol 2012;2012:106746.

6. Wang SJ, Zheng CJ, Peng C, Zhang H, Jiang YP, Han T, et al. Plants and cervical cancer: An overview. Expert Opin Investig Drugs 2013;22:1133-56.

7. Lee MS, Jung S, Moon HI, Ohk J, Lee S, Li C, et al. Inhibitory effect and mechanism of antiproliferation of isoatriplicolide tiglate (PCAC) from Paulownia coreana. Molecules 2013;18:2587-2588. 
8. Rajendran S, Saravanan R, Ramalingam S, Hameed SA. Antiproliferative and antioxidant activity of Gynandropsis pentaphylla Linn on MCF-7 cell line. Int J Pharm Pharm Sci 2014;6:561-5.

9. Preethy CP, Padmapriya R, Periasamy VS, Riyasdeen A, Srinag S, Krishnamurthy $\mathrm{H}$, et al. Antiproliferative property of n-hexane and chloroform extracts of Anisomeles malabarica (L). R. Br. In HPV16positive human cervical cancer cells. J Pharmacol Pharmacother 2012;3:26-34.

10. Seeram NP, Adams LS, Zhang Y, Lee R, Sand D, Scheuller HS, et al. Blackberry, black raspberry, blueberry, cranberry, red raspberry, and strawberry extracts inhibit growth and stimulate apoptosis of human cancer cells in vitro. J Agric Food Chem 2006;54:9329-39.

11. Han C, Ding H, Casto B, Stoner GD, D'Ambrosio SM. Inhibition of the growth of premalignant and malignant human oral cell lines by extracts and components of black raspberries. Nutr Cancer 2005;51:207-17.

12. Zhang Z, Knobloch TJ, Seamon LG, Stoner GD, Cohn DE, Paskett ED, et al. A black raspberry extract inhibits proliferation and regulates apoptosis in cervical cancer cells. Gynecol Oncol 2011;123:401-6.

13. Beghelli D, Isani G, Roncada P, Andreani G, Bistoni O, Bertocchi M, et al. Antioxidant and ex vivo immune system regulatory properties of Boswellia serrata extracts. Oxid Med Cell Longev 2017;2017:1-10.

14. Kooti W, Servatyari K, Behzadifar M, Asadi-Samani M, Sadeghi F, Nouri B, et al. Effective medicinal plant in cancer treatment, Part 2: Review study. J Evid Based Complementary Altern Med 2017;22:982-95.

15. Khan MS, Ansari IA, Ahmad S, Akhter F, Hashim A, Srivastava AK. Chemotherapeutic potential of Boerhaavia diffusa Linn: A review. J Appl Pharm Sci 2013;3:133-9.

16. Srivastava R, Saluja D, Dwarakanath BS, Chopra M. Inhibition of human cervical cancer cell growth by ethanolic extract of Boerhaavia diffusa linn. (Punarnava) root. Evid Based Complement Alternat Med 2011:2011:427031.

17. Venkatajothi R. In-vitro anticancer activity of Boerhaavia diffusa Linn. Int J Curr Res Biol Med 2017;2:20-4

18. Ganesh G, Abhishek T, Saurabh M, Sarada NC. Cytotoxic and apoptosis induction potential of Mimusops elengi L. in human cervical cancer (SiHa) cell line. J King Saud Univ Sci 2014;26:333-7.

19. Rejiya CS, Cibin TR, Abraham A. Leaves of Cassia tora as a novel cancer therapeutic-an in vitro study. Toxicol In Vitro 2009;23:1034-8.

20. Koppikar SJ, Choudhari AS, Suryavanshi SA, Kumari S, Chattopadhyay S, Kaul-Ghanekar R, et al. Aqueous cinnamon extract (ACE-c) from the bark of Cinnamomum cassia causes apoptosis in human cervical cancer cell line $(\mathrm{SiHa})$ through loss of mitochondrial membrane potential. BMC Cancer 2010;10:210.

21. Rahman A, Hussain A. Anti-cancer activity and apoptosis inducing effect of methanolic extract of Cordia dichotoma against human cancer cell line. J Bangladesh Pharm Soc (BDPS) 2015;10:27-34.

22. Saengkrit N, Saesoo S, Srinuanchai W, Phunpee S, Ruktanonchai UR. Influence of curcumin-loaded cationic liposome on anticancer activity for cervical cancer therapy. Colloids Surf B Biointerfaces 2014;114:349-56.

23. Kumar D, Basu S, Parija L, Rout D, Manna S, Dandapat J, et al. Curcumin and ellagic acid synergistically induce ROS generation, DNA damage, p53 accumulation and apoptosis in heLa cervical carcinoma cells. Biomed Pharmacother 2016;81:31-7.

24. Merghoub N, Benbacer L, Amzazi S, Morjani H, Mzibri ME. Cytotoxic effect of some Moroccan medicinal plant extracts on human cervical cell lines. J Med Plants Res 2009;3:1045-50.

25. Jeong YT, Yang BK, Jeong SC, Kim SM, Song CH. Ganoderma applanatum: A promising mushroom for antitumor and immunomodulating activity. Phytother Res 2008;22:614-9.

26. Hakkim FL, Al-Buloshi M, Achankunju J. Chemical composition and anti-proliferative effect of Oman's Ganoderma applanatum on breast cancer and cervical cancer cells. J Taibah Univ Med Sci 2016;11:145-51.

27. Zhang L, Feng J, Kong S, Wu M, Xi Z, Zhang B, et al. Nujiangexathone A, a novel compound from Garcinia nujiangensis, suppresses cervical cancer growth by targeting hnRNPK. Cancer Lett 2016;380:447-56.

28. Chueahongthong F, Ampasavate C, Okonogi S, Tima S, Anuchapreeda S. Cytotoxic effects of crude kaffir lime (Citrus hystrix, DC.) leaf fractional extracts on leukemic cell lines. J Med Plants Res 2011;5:3097-105.

29. Tunjung WA, Cinatljr J, Michaelis M, Smales CM. Anti-cancer effect of kaffir lime (Citrus hystrix DC) leaf extract in cervical cancer and neuroblastoma cell lines. Procedia Chem 2015;14:465-8.

30. Jain S, Dwivedi J, Jain PK, Satpathy S, Patra A. Medicinal plants for treatment of cancer: A brief review. Pharmacog J 2016;8:87-102.

31. Kma L. Roles of plant extracts and constituents in cervical cancer therapy. Asian Pac J Cancer Prev 2013;14:3429-36.

32. Tan GC, Wong KM, Wong GQ, Yeo SL, Yeap SK, Yiap BC, et al. In vitro cytotoxic and antiproliferative effects of Portulaca oleracea methanol extract on breast, cervical, colon and nasopharyngeal cancerous cell les. Sains Malaysiana 2013;42:927-35.

33. Azarifar Z, Mortazavi M, Farhadian R, Parvari S, Roushnadeh AM. Cytotoxicity effects of aqueous extract of Purtulaca oleracea on HeLa cell line. Pharm Sci 2015;21:41-5.

34. Mohammad R, Hossein B, Davood F, Farnaz T, Ali F, Yusef R. The apoptotic and cytotoxic effects of Polygonum avicular extract on Hela-S cervical cancer cell line. Afr J Biochem Res 2011;5:373-8.

35. Kumar A, Deepa B, Saravanan R, Hameed SA. Reactive oxygen and nitrogen species scavenging and anticancer potential of Cissus quadrangularis L. against EAC cell line. Int J Pharm Pharm Sci 2014:6:269-74.

36. Shoushtar AB, Sazgar H, Pirbaloti AG. Cytotoxic effect of hydroalcoholic extract from Satureja bachtiarica bunge on HeLa cancer cell line. J Herb Drugs 2017;7:223-9.

37. Li J, Li Q, Feng T, Li K. Aqueous extract of Solanum nigrum inhibit growth of cervical carcinoma (U14) via modulating immune response of tumor bearing mice and inducing apoptosis of tumor cells. Fitoterapia 2008; 79:548-56.

38. Mousavi SH, Naghizade B, Pourgonabadi S, Ghorbani A. Protective effect of viola tricolor and viola odorata extracts on serum/glucose deprivation-induced neurotoxicity: Role of reactive oxygen species. Avicenna J Phytomed 2016;6:434-41.

39. Bachrach ZY. Contribution of selected medicinal plants for cancer prevention and therapy. Sci J Fac Med Niš 2012;29:117-23.

40. Esmaeili MA, Abagheri-Mahabadi N, Hashempour H, Farhadpour M, Gruber CW, Ghassempour A, et al. Viola plant cyclotide vigno 5 induces mitochondria-mediated apoptosis via cytochrome $C$ release and caspases activation in cervical cancer cells. Fitoterapia 2016;109:162-8.

41. Adaramoye OA, Sarkar J, Singh N, Meena S, Changkija B, Yadav PP, et al. Antiproliferative action of Xylopia aethiopica fruit extract on human cervical cancer cells. Phytother Res 2011;25:1558-63.

42. Su K, Wang CF, Zhang Y, Cai YJ, Zhang YY, Zhao Q, et al. The inhibitory effects of carnosic acid on cervical cancer cells growth by promoting apoptosis via ROS-regulated signaling pathway. Biomed Pharmacother 2016;82:180-91

43. Chan LL, George S, Ahmad I, Gosangari SL, Abbasi A, Cunningham BT, et al. Cytotoxicity effects of Amoora rohituka and chittagonga on breast and pancreatic cancer cells. Evid Based Complement Alternat Med 2011;2011:860605.

44. Umadevi M, Kumar KP, Bhowmik D, Duraivel S. Traditionally used anticancer herbs in India. J Med Plants Stud 2013;1:56-74.

45. Jagetia GC, Venkatesa VA. Determination of antineoplastic activity of rohituka, Aphanamixis polystachya (Wall) RN parker in hela cells: Correlation with clonogenicity and DNA damage. Int J Complementary Altern Med 2016,3:1-11.

46. Frías González SE, Angeles Anguiano E, Mendoza Herrera A, Escutia Calzada D, Ordaz Pichardo C. Cytotoxic, pro-apoptotic, pro-oxidant, and non-genotoxic activities of a novel copper(II) complex against human cervical cancer. Toxicology 2013;314:155-65.

47. Zhang GL, Jiang L, Yan Q, Liu RH, Zhang L. Anti-tumor effect of matrine combined with cisplatin on rat models of cervical cancer. Asian Pac J Trop Med 2015;8:1055-9.

48. Kanimozhi G, Prasad NR. Anticancer Effect of Caffeic Acid on Human Cervical Cancer Cells; 2015. p. 655-661.

49. Di Domenico F, Foppoli C, Coccia R, Perluigi M. Antioxidants in cervical cancer: Chemopreventive and chemotherapeutic effects of polyphenols. Biochim Biophys Acta 2012;1822:737-47.

50. Chakrabarty S, Ganguli A, Das A, Nag D, Chakrabarti G. Epigallocatechin-3-gallate shows anti-proliferative activity in heLa cells targeting tubulin-microtubule equilibrium. Chem Biol Interact 2015;242:380-9.

51. Zou C, Liu H, Feugang JM, Hao Z, Chow HH, Garcia F, et al. Green tea compound in chemoprevention of cervical cancer. Int J Gynecol Cancer 2010;20:617-24.

52. Ahn WS, Huh SW, Bae SM, Lee IP, Lee JM, Namkoong SE, et al. A major constituent of green tea, EGCG, inhibits the growth of a human cervical cancer cell line, CaSki cells, through apoptosis, G1 arrest, and regulation of gene expression. DNA Cell Biol 2003;22:217-24.

53. Oliveira C, Nicolau A, Teixeira JA, Domingues L. Cytotoxic effects of native and recombinant frutalin, a plant galactose-binding lectin, on heLa cervical cancer cells. J Biomed Biotechnol 2011;2011:568932.

54. Sourani Z, Pourgheysari B, Beshkar P, Shirzad H, Shirzad M. Gallic acid inhibits proliferation and induces apoptosis in lymphoblastic leukemia cell line (C121). Iran J Med Sci 2016;41:525-30.

55. Shi L, Lei Y, Srivastava R, Qin W, Chen JJ. Gallic acid induces apoptosis 
in human cervical epithelial cells containing human papillomavirus Type 16 episomes. J Med Virol 2016;88:127-34.

56. Raffoul UJ, Wang Y, Kucuk O, Forman JD, Sarkar FH, Hillman GG. Genistein inhibits radiation-induced activation of NF-kB in prostate cancer cells promoting apoptosis and $\mathrm{G} 2 / \mathrm{M}$ cell cycle arrest. BMC Cancer 2006;6:1-10.

57. Yashar CM, Spanos WJ, Taylor DD, Gercel-Taylor C. Potentiation of the radiation effect with genistein in cervical cancer cells. Gynecol Oncol 2005;99:199-205.

58. Moga MA, Dimienescu OG, Arvatescu CA, Mironescu A, Dracea L, Ples L, et al. The role of natural polyphenols in the prevention and treatment of cervical cancer-an overview. Molecules 2016;21:1-32.

59. Yao Z, Shulan Z. Inhibition effect of guizhi-fuling-decoction on the invasion of human cervical cancer. J Ethnopharmacol 2008;120:25-35

60. Alshatwi AA, Ramesh E, Periasamy VS, Subash-Babu P. The apoptotic effect of hesperetin on human cervical cancer cells is mediated through cell cycle arrest, death receptor, and mitochondrial pathways. Fundam Clin Pharmacol 2013;27:581-92.

61. Lin L, Cheng XL, Li MZ, Wang T, Dong MH, Wang ZY, et al. Antitumor effects of iridomyrmecin in HeLa cervical cancer cells are mediated via apoptosis induction, loss of mitochondrial membrane potential, cell cycle arrest and down-regulation of PI3K/Akt and up-regulation of lncRNA CCAT2 expression. Bangladesh J Pharmacol 2016;11:856-62.

62. Hsu YL, Chia CC, Chen PJ, Huang SE, Huang SC, Kuo PL, et al. Shallot and licorice constituent isoliquiritigenin arrests cell cycle progression and induces apoptosis through the induction of ATM/p53 and initiation of the mitochondrial system in human cervical carcinoma heLa cells. Mol Nutr Food Res 2009;53:826-35.

63. Song X, Liu CC, Hong YR, Zhu XC. Anticancer activity of novel oleanolic acid methyl ester derivative in HeLa cervical cancer cells is mediated through apoptosis induction and reactive oxygen species production. J Bangladesh Pharmacol Soc (BDPS) 2015;10:896-902.

64. Chen YJ, Kay N, Yang JM, Lin CT, Chang HL, Wu YC, et al. Total synthetic protoapigenone WYC02 inhibits cervical cancer cell proliferation and tumour growth through PIK3 signalling pathway. Basic Clin Pharmacol Toxicol 2013;113:8-18.

65. Sharma G, Rana NK, Singh P, Dubey P, Pandey DS, Koch B, et al. P53 dependent apoptosis and cell cycle delay induced by heteroleptic complexes in human cervical cancer cells. Biomed Pharmacother 2017;88:218-31

66. Kostova I. Ruthenium complexes as anticancer agents. Curr Med Chem 2006;13:1085-107.

67. Li J, Li Q, Feng T, Zhang T, Li K, Zhao R, et al. Antitumor activity of crude polysaccharides isolated from Solanum nigrum linne on U14 cervical carcinoma bearing mice. Phytother Res 2007;21:832-40.

68. Govind P. Some important anticancer herbs: A review. Int Res J Pharm 2011;2:45-52

69. Gbadamosi IT, Afolayan AJ. In vitro anti-radical activities of extracts of Solanum nigrum (L.) from South Africa. J Appl Biosci 2016;98:9240-51.

70. Miraj S. Solanum nigrum: A review study with anti-cancer and antitumor perspective. Pharm Chem 2016;8:62-68.

71. Atanu FO, Ebiloma UG, Ajayi EI. A review of the pharmacological aspects of Solanum nigrum Linn. Biotechnol Mol Biol Rev 2011;6:1-7.

72. Sharma C, Sadrieh L, Priyani A, Ahmed M, Hassan AH, Hussain A, et al. Anti-carcinogenic effects of sulforaphane in association with its apoptosis-inducing and anti-inflammatory properties in human cervical cancer cells. Cancer Epidemiol 2011;35:272-8.

73. Alshatwi AA, Periasamy VS, Athinarayanan J, Elango R. Synergistic anticancer activity of dietary tea polyphenols and bleomycin hydrochloride in human cervical cancer cell: Caspase-dependent and independent apoptotic pathways. Chem Biol Interact 2016;247:1-0.

74. Munagala R, Kausar H, Munjal C, Gupta RC. Withaferin A induces p53-dependent apoptosis by repression of HPV oncogenes and upregulation of tumor suppressor proteins in human cervical cancer cells. Carcinogenesis 2011;32:1697-705. 